\title{
Abiological catalysis for synthetic efficiency
}

\author{
Barry M. Trost \\ Department of Chemistry, Stanford University, Stanford, CA 94305-5080
}

\begin{abstract}
Synthetic efficiency requires reactions that are both selective and economical in terms of atom count. The invention of new transition metal catalyzed reactions provides a powerful approach to both problems. Palladium complexes have been particularly fruitful in creating new reactions. By use of such complexes to resolve a chemoselectivity problem, cyclizations to medium sized rings becomes efficient. An approach for controlling regioselectivity in palladium catalyzed allylic alkylations invokes tethering two reactants either by hydrogen bonding or covalently. The metal complex may become a template to impose diastereoselectivity that violates the thermodynamic preferences of the product. A new type of chiral environment to promote enantioselectivity now allows asymmetric $\mathrm{C}$ - $\mathrm{C}$ bond formation in excess of $95 \%$ ee. These methods evolve efficient syntheses of glycosidase inhibitors allosamidine and mannostatin A. While many of these methods are atom economical, this goal requires exploration of other processes. Transition metal catalyzed reactions of acetylenes are particularly fruitful territory for exploration. Palladium catalyzed isomerization of acetylenes to allenes and insertion into acetylenic $\mathrm{C}-\mathrm{H}$ bonds provide two new processes, both of which when applied intramolecularly effect cycloisomerization to macrocycles. Palladium complexes are not unique in their synthetic utility. A ruthenium catalyzed condensation of allyl alcohols and terminal acetylenes constitutes an effective synthesis of $\beta, \gamma-$ unsaturated ketones which is a simple addition of the two reactants with reorganization of the oxidation pattern.
\end{abstract}

\section{INTRODUCTION}

Enhanced challenges for organic synthesis come from the rapidly expanding need for highly sophisticated molecules. Meeting this challenge requires enhanced synthetic efficiency in going from readily available building blocks to the desired complicated targets. Chemo-, regio-, diastereo- and enantioselectivity represents a key aspect of efficiency. In addition, effective use of raw materials which might be referred to as atom economy must also be considered a prime, often times overlooked, goal. In the extreme, the product should be the simple sum of the reactants with no additional stoichiometric reagents required. The benefits of such processes are immense, not only in terms of maximum use of mass, but also of minimal waste disposal. Whereas, selectivity has dominated our thinking in the decade of the 1980's; atom economy must be considered of co-equal importance for the decade of the 1990's. Catalysis using transition metal complexes provides a major strategy to address the full scope of the problems of synthetic efficiency. In this overview, our attempts to address problems in each of this categories by use of abiological catalysts are outlined.

\section{CHEMOSELECTIVITY}

One intriguing problem of chemoselectivity arises in the formation of rings of more than seven members wherein the battle derives from intermolecular processes leading to polymerization competing with the desired intramolecular process. We have broached this problem by examining the palladium catalyzed cycloisomerization of vinyl epoxides (eq 1) (ref 1,2). To obviate the problem of polymerization, such cyclizations normally require high dilution. In this case, utilizing an insoluble polymer supported palladium catalyst in which the two phase system constititutes pseudo-<smiles>O=C(COC(=O)Oc1ccccc1)OCCCCCCCCCC=CC1CO1</smiles><smiles>O=C(O)C(=O)OCCCCCCCCCCC(/C=C/CO)C(=O)O</smiles>

high dilution conditions, the cyclization proceeds in $70 \%$ yield at $0.2 \mathrm{M}$ concentration. Medium sized ring compounds $(8,9$ and 10$)$ represent the most challenging targets since most cyclization methods applied to these ring sizes either fail or proceed in very low yields even at high dilution. Of these ring sizes, the ten membered ring would be the most approachable. In a program directed toward the synthesis of taxanes, we investigated the cyclization of (eq 2) (ref 3).<smiles>C=C(C)C1OC1CC1(C)CCCC=C1CC(=O)COc1ccccc1</smiles><smiles>CC(C)C(C(C)(C)C)C(C)(C)C</smiles><smiles>C/C1=C/C(O)CC2(C)CCCC=C2CC(=O)C(S(=O)(=O)O)CC1S(=O)(=O)O</smiles> 
The choice of ligand proved crucial. Triphenyl phosphine and dppp proved ineffective as did our increasingly preferred triisopropyl phosphite. Trifuryl phosphine in combination with (dba) ${ }_{3} \mathrm{Pd}_{2} \cdot \mathrm{CHCl}_{3}$ (1) catalyzed cyclization effectively to produce the desired cylodecenone in $80-90 \%$ yields.

The nine member ring becomes more challenging considering the competition with seven member ring formation exists. Nevertheless, the $10^{4}$ bias for seven membered ring formation is completely overcome and only<smiles>C=CC1C(O)CCCCC1(Oc1ccccc1)c1ccccc1</smiles>

nine membered ring formation is observed in $63 \%$ yield (eq 3) (ref 4). The delicate balance that exists is revealed in the next lower homologue in which only the cyclohexyl product ( $85 \%$ yield) is observed (eq 4 ) under identical conditions.<smiles>C=CC1C(O)CCCC1(c1ccccc1)S(=O)(=O)Oc1ccccc1</smiles><smiles>C=CC1OC1CCC(Oc1ccccc1)C(=O)OC1CC1C</smiles><smiles>CC(C)(C)C</smiles><smiles>O=C1OC(O)C=CCC1(Oc1ccccc1)Oc1ccccc1</smiles>

Nevertheless, by judicious modification of the substrate to disfavor six member ring formation, eight member carbocyclic rings do form in good yields (eq5) (ret 5). These metal catalyzed cyclizations clearly challenge the<smiles>C=CC1(S(=O)(=O)c2ccccc2)CCCCC(C=C)(S(=O)(=O)c2ccccc2)OC1</smiles>
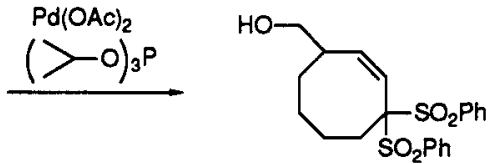

traditional concepts of preferential ring formation and permit entry to virtually every ring size - even the most difficult medium sized rings.

\section{REGIOSELECTIVITY}

Obviously, in all of these cases, the question of regioselectivity arises. As exemplified, ring size does not dominate this method of cyclization. Considering the case of vinyl epoxide terminators, the normal bias for carbon nucleophiles is to attack the intermediate $\pi$-allylpalladium complex at the $\pi$-allyl terminus distal to the oxygen. Heteroatom nucleophiles, however, show quite different behavior. As exemplified in eq 6 , reaction proceeds preferentially proximal in THF in $56 \%$ yield (ref 6). A rationale invokes tethering of the pro-nucleophile to the departing epoxide

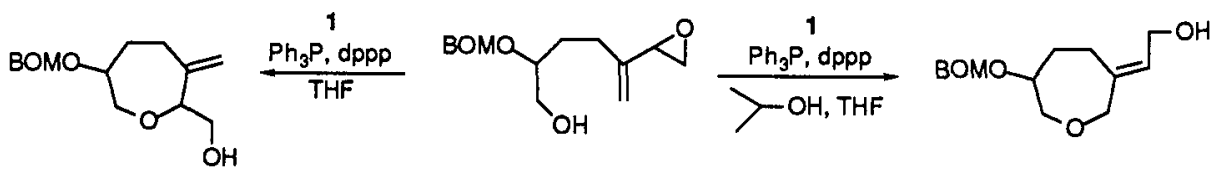

oxygen by hydrogen bonding thereby delivering the nucleophile to the proximal carbon. In agreement with this hypothesis, running the reaction in $4: 1$ isopropanol-THF reorients the two reactants such that only attack distal to the epoxide oxygen occurs in $52 \%$ yield to give a zoapatanol ring system.

Covalent tethering of the nucleophile to the departing oxygen should provide a general approach to proximal versus distal attack. As shown in eq 7 (ref 7 ) and 8 (ref 8 ), using carbon dioxide and isocyanates as pro-nucleophiles leads clearly to the five member heterocycles, the former in a total synthesis of $(+)$-citreoviral.

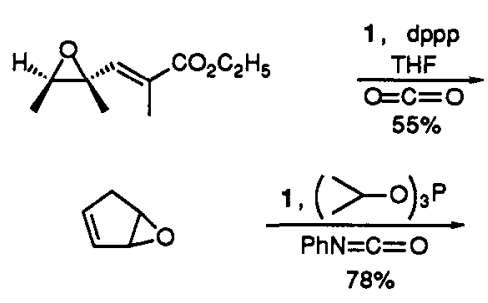<smiles>CCOC(C)=C1OC(=O)OC1(C)C</smiles> 


\section{DIASTEREOSELECTIVITY}

Metal catalyzed reactions offer the opportunity to control the stereochemical course of reactions by extrinsic rather than intrinsic factors as illustrated in eq 9 for $\pi$-allylpalladium chemistry. Thus, the interactions of $R_{L}$ with the metal<smiles>[R9]C1(C=CC)CCCN1</smiles>

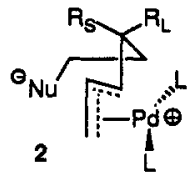

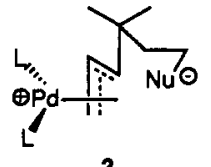

3<smiles>[R1]C1(C=C)CCN[C@H]1C</smiles>

"template" in $\mathbf{2}$ destabilizes it relative to 3 in spite of the enhanced interaction of $R_{L}$ with the forming ring in the latter thereby providing the contrathermodynamic product 4 . The first illustration of this phenomenon arose in the reactions of isocyanates which has been optimized by the use of 2-methoxy-1-naphthyl isocyanate. As shown in eq 10 , either isomer of the initial vinyl epoxide leads to the same product in which the thermodynamically less stable

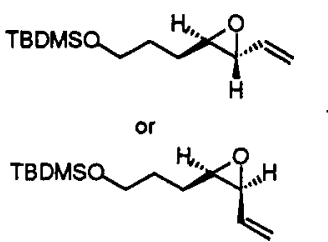<smiles>COc1ccc2ccccc2c1N=C=O</smiles>

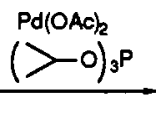<smiles>C=CC1[C@H](CCCOC(C)C)OC(=O)N1c1c(OC)ccc2ccccc12</smiles>

isomer was the exclusive product in $80-100 \%$ yield (ref 9 ). Thesame principle applies to carbocycles as illustrated in eq 11 in which the $Z$ isomer dominated to the extent of about $7: 1$ (82-94\% yield) (ref 10$)$. This phenomenon appears

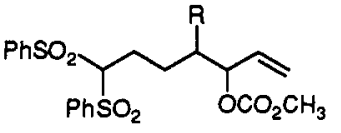

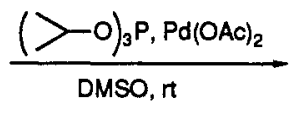<smiles>[R]C1CCC(S(=O)(=O)c2ccccc2)(S(=O)(=O)c2ccccc2)C1C=C</smiles>

$\mathrm{R}=\mathrm{CH}_{3}, \mathrm{CH}_{2} \mathrm{Ph}, \mathrm{iC}_{3} \mathrm{H}_{7}$

to be reasonably general for formation of five membered rings. Cyclization via O-alkylation generates the alkylidenetetrahydrofuran with 6.2:1 Z:E as in eq 12 . Thus, the transition metal complex can function as a template

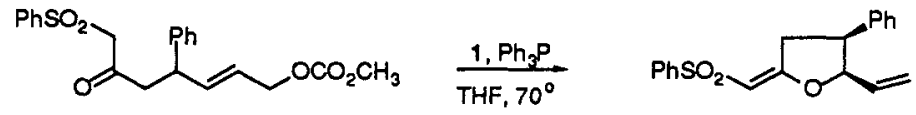

to impose a stereochemical course that violates the intrinsic thermodynamics of the substrate.

\section{ENANTIOSELECTIVITY}

A major aspect of any catalysis is the control of absolute stereochemistry. In $\pi$-allylpalladium complexes, four types of situations exist as outlined in Figure 1. In conjunction with our investigation ion the synthesis of glycosidase inhibitors, we became interested in the Type III process with respect to cis-3,5-dihydroxycyclopentene and its

TYPE I

ENANTIOFACIAL RECOGNITION<smiles>[X]C/C=C\[R]([Z])=[Te]</smiles>

TYPE III

ENANTIOTOPIC LEAVING GROUP<smiles>[X]CC=C(C[Z])[Te]C[CH]</smiles>

TYPE II

KINETIC RESOLUTION<smiles>[R]C=C(C)[Ge]([3H])=C[Z]</smiles>

TYPE IV

Flgure 1. Asymmetric Induction in $\pi$-Allylpalladlum ChemIstry 
derivatives 5 as outlined in eq 13.<smiles>[R]C1C2CC(I)C(C2)C1O</smiles><smiles>[B]C1C=C[C@@H]2[C@H]1OC(=O)N2[13CH2]</smiles>

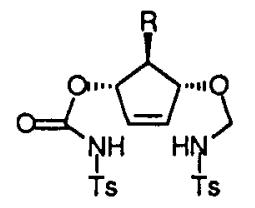<smiles>CCCCC</smiles>

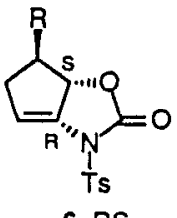

In our original efforts, we focussed on S-BINAPO (6) - a very convenient ligand which we previously showed gave high ee in Type IV asymmetric induction (ref 11). Gratifyingly, the one pol conversion of $5\left(\mathrm{R}=\mathrm{CH}_{2} \mathrm{OCH}_{2} \mathrm{Ph}\right)$ into 6-RS $\left(\mathrm{R}=\mathrm{CH}_{2} \mathrm{OCH}_{2} \mathrm{Ph}\right)$ proceeded with $65 \%$ ee (ref 12$)$. Since the $\mathrm{R}$ group projects onto the same face of the cyclopentene to which the palladium must coordinate, its influence on the ee was examined. Indeed, under identical conditions, $5(R=H)$ produced 6 of only $28 \%$ ee (ref 13$)$.

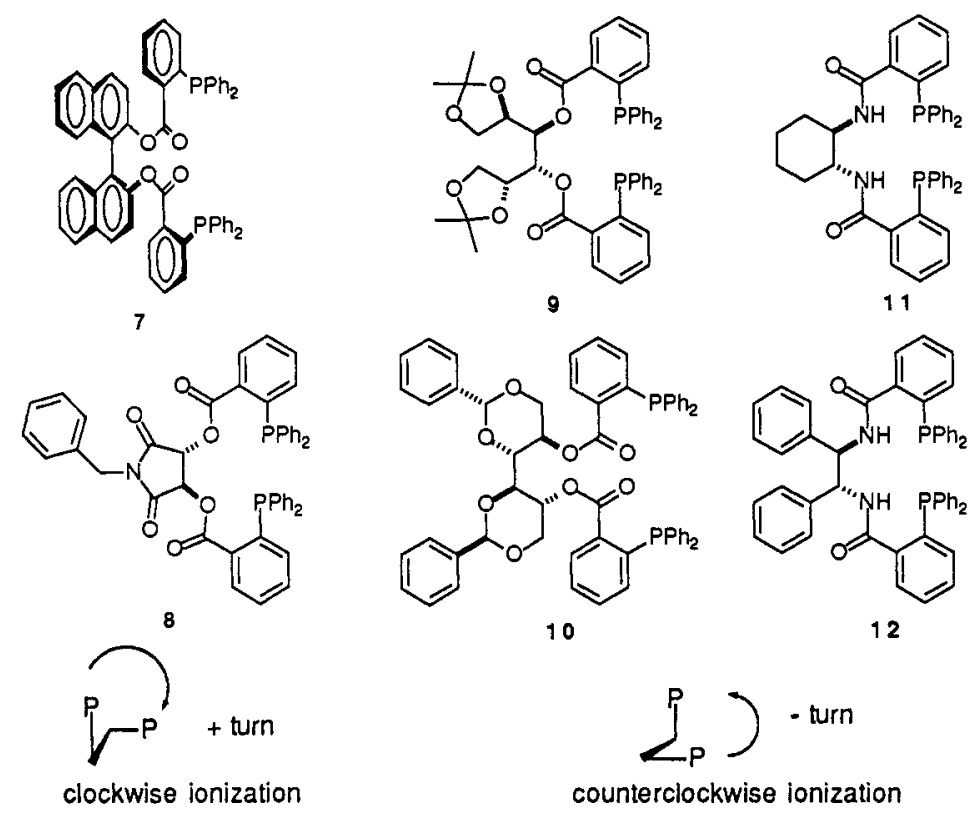

Figure 2. Asymmetric Ligands

Keeping in mind that in these reactions, all bond breaking and bond making occurs on the face opposite to palladium, we must design the ligand such that they embrace the olefin and/or the $\pi$-allyl moieties to create the requisite asymmetric environment for high chiral recognition along the reaction coordinate. We have previously suggested that the "bite angle" (ie the L"-Pd-L" angle) may correlate with the degree of embracing since opening this angle should force the substitutents on phosphorus (and thus the chiral environment) towards the olefin or $\pi$-allyl moieties. Keeping in mind that we want the ligands to be as simple as possible, we turned to esters and amides of readily available enantiomerically pure alcohols and amines and 2-diphenylphosphinobenzoic acid. The conversion of eq $13(R=H)$ was explored as our model (ref 13 ).

Not unexpectedly, use of catalysts possessing ligands derived from non- $\mathrm{C}_{2}$ symmetric chiral alcohols and amines gave very poor enantioselectivities. On the other hand, the diester from S-binaphthol 7 (see Figure 2) increased the ee to $40 \%$. Enforcing more conformational rigidity as in the case of the tartrate 8 enhances the ee to $75 \%$. Both of these ligands give 6-RS. This absolute stereochemistry can be correlated with the helical twist of the bidentate ligands as indicated in Fig 2. By looking along the axis connecting the stereogenic centers, the two diphenylphosphino groups can be viewed as making a clockwise or $(+)$-turn and consequently initiating selective ionization of the pro-R leaving group by a clockwise twist in the ionization step (the asymmetric inducing step).

Utilizing ligands that would create a counterclockwise or $(-)$ turn should initiate ionization by a counterclockwise twist in the ionization step. Of course, the enantiomers of 7 and 8 fall into this category. The mannose derivatives 9 and 10 also fall into this category and give satisfactory $64 \%$ and $61 \%$ ee respectively. Introducing more rigidity by replacing the ester linkage with an amide linkage as in 11 and 12 jumps the ee to $78 \%$ and $80 \%$ respectively. Ring size does play a role since the cyclohexene system 13 provides the oxazolidin-2-one in $90 \%$ ee (eq 14). 


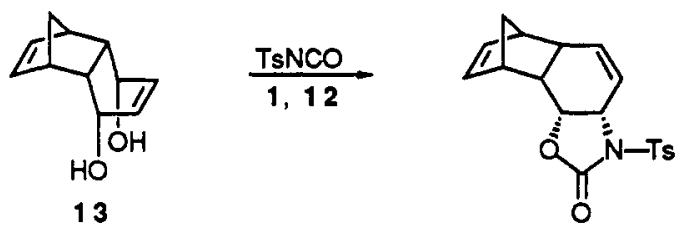

Since the asymmetric recognition comes in the ionization step, the leaving group should also play some role whereas the nucleophile should not. These two effects were probed with the anion of phenylsulfonylnitromethane and the diphenylacetate ester of 5 (eq 15). In this case, the ee exceeded 95\%! (ref 14) An unusual new class of heterocycles which can be quite valuable for the synthesis of carbanucleosides is produced.<smiles>CC(C)C(C)C(C)C</smiles>

These methods nicely accommodate synthetic strategies to the biologically interesting glycosidase inhibitors allosamidine and mannostatin $A$. The chitinase inhibitor allosamidine (13) is a pseudotrisaccharide comprised of two molecules of allosamine and one of allosamizoline (14, R=H) (ref 15). Scheme 1 outlines an extremely efficient synthesis of allosamizoline in which our synthesis of oxazolidin-2-ones plays a pivotal role (ref 12). The olefin 15 provides a convenient entry to all four diastereomeric diols to confirm the structure of this pseudomonosaccharide.

\section{Scheme 1}

\section{A Synthesis of Allosamizoline}

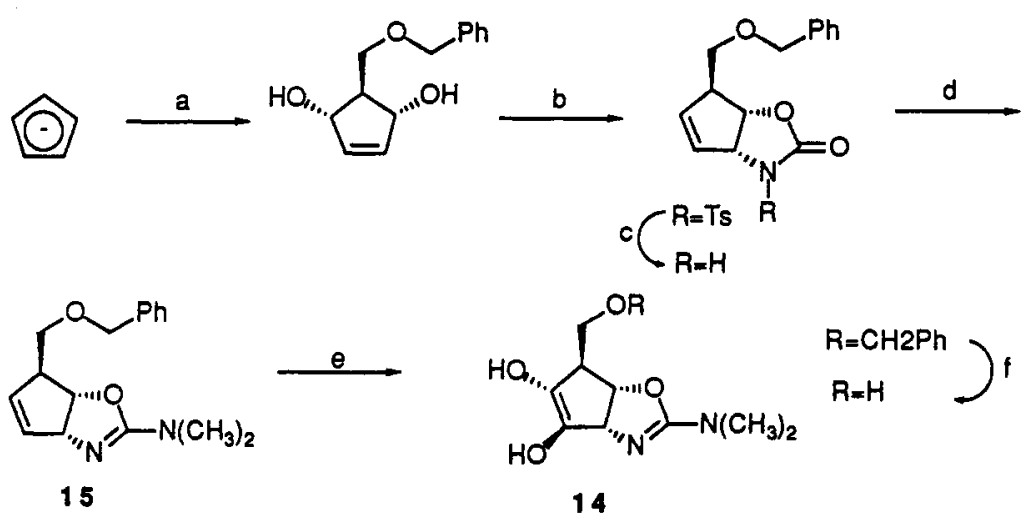

a) $\mathrm{PhCH}_{2} \mathrm{OCH}_{2} \mathrm{Cl}$, ether, $-20^{\circ}$ then $\mathrm{O}_{2}$, methylene blue, $\mathrm{CH}_{3} \mathrm{OH}, v 2,0^{\circ}$, thiourea; $33 \%$. b) Two eq. TsNCO, THF then $1\left(\mathrm{iC}_{3} \mathrm{H}_{3} \mathrm{O}\right)_{3} \mathrm{P}, \mathrm{THF}, \mathrm{rt} ; 93 \%$. c), $\mathrm{Na}$, naphthalene, DME, $-78^{\circ} \mathrm{C} ; 91 \%$. d) $\mathrm{CF}_{3} \mathrm{SO}_{3} \mathrm{CH}_{3}, \mathrm{CH}_{2} \mathrm{Cl}_{2}$ then $\left(\mathrm{CH}_{3}\right)_{2} \mathrm{NH} ; 100 \%$. e) $\mathrm{CF}_{3} \mathrm{CO}_{3} \mathrm{H}, \mathrm{CF}_{3} \mathrm{CO}_{2} \mathrm{H}, 0^{\circ}$ then $\mathrm{CF}_{3} \mathrm{CO}_{2} \mathrm{H}$, $\mathrm{H}_{2} \mathrm{O}$; f) $40 \mathrm{psi} \mathrm{H}_{2}, \mathrm{Pd} / \mathrm{C}, \mathrm{CH}_{3} \mathrm{OH}, \mathrm{rt} ; 67 \%$ overall.

Coupling of the monobenzyl ether $14\left(R=\mathrm{CH}_{2} \mathrm{Ph}\right)$ with the disaccharide 16 followed by deblocking completes a synthesis of the chitinase inhibitor (eq 16) (ref 16).

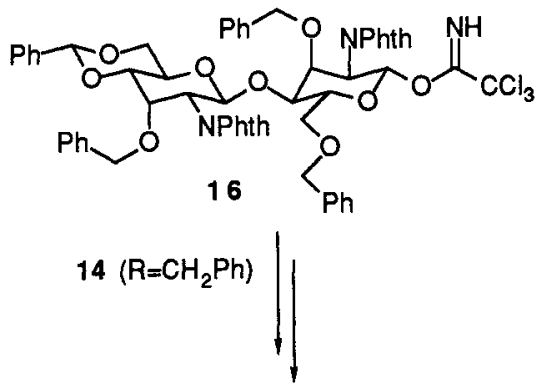

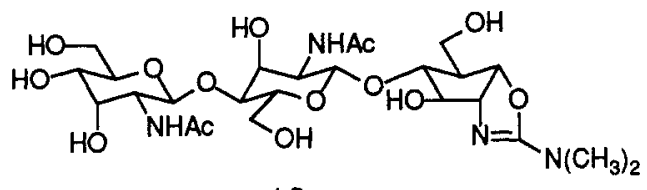


Scheme 2

A Synthesis of Mannostatin

HO,<smiles>C[C@H]1C=C[C@@H](O)C1</smiles><smiles></smiles><smiles>C1CCCC1</smiles>

17<smiles>O=C1O[C@H]2[C@H](C=C[C@H]2O)N1[AsH3]</smiles><smiles>C=CC</smiles><smiles>O[C@H]1[C@H](O)C=C[C@H]1[PH3-]</smiles><smiles>C1CCCC1</smiles><smiles>[PbH]</smiles>

$\mathrm{R}, \mathrm{R}=\mathrm{C}\left(\mathrm{CH}_{3}\right)_{2}$<smiles>[13CH3]N1C(=O)O[C@H]2C(=O)C=C[C@H]21</smiles>

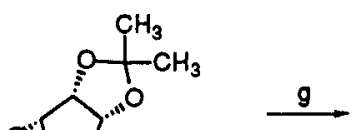

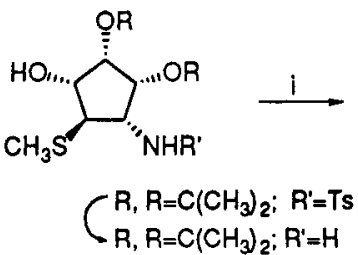<smiles>CS[C@H]1[C@@H](N)[C@H](O)[C@@H](O)[C@@H]1O</smiles>

a) Two eq TsNCO, THF then 1, $\left(\mathrm{iC}_{3} \mathrm{H}_{7} \mathrm{O}\right)_{3} \mathrm{P}$, reflux; $97 \%$. b) $\mathrm{SeO}_{2}, \mathrm{Na}_{2} \mathrm{HPO}_{4}$, quartz sand, diglyme, $170^{\circ}$ then Dess-Martin periodinane, $\mathrm{NaHCO}_{3}, \mathrm{CH}_{2} \mathrm{Cl}_{2}, \mathrm{r}, 65 \%$. c) $\mathrm{NaBH}_{4}, \mathrm{CeCl}_{3}$, $\mathrm{CH}_{3} \mathrm{OH}, \mathrm{C}_{2} \mathrm{H}_{5} \mathrm{OAC},-50 ; 83 \%$. d) $\mathrm{K}_{2} \mathrm{CO}_{3}, \mathrm{CH}_{3} \mathrm{OH}, \mathrm{H}_{2} \mathrm{O}$, et; $95 \%$. e) $\left.\left(\mathrm{CH}_{3}\right)_{2} \mathrm{C}(\mathrm{O}) \mathrm{CH}_{3}\right)_{2}$, $\left(\mathrm{CH}_{3}\right)_{2} \mathrm{CO}, \mathrm{CSA}, \mathrm{r} ; 93 \%$. f) $\mathrm{CF}_{3} \mathrm{CO}_{3} \mathrm{H}, \mathrm{Na}_{2} \mathrm{HPO}_{4}, \mathrm{CH}_{2} \mathrm{Cl}_{2} ; 90 \%$. g) $\mathrm{CH}_{3} \mathrm{SLi}$, THF, $-78^{\circ}$ to $\mathrm{n}$; $78 \%$. h) $\mathrm{Na}, \mathrm{NH}_{3} ; 97 \%$. i) $60 \%$ aq. $\mathrm{CF}_{3} \mathrm{CO}_{2} \mathrm{H}, 60^{\circ}$.

The corresponding oxazolidin-2-one 17 also serves as a pivotal intermediate for the synthesis of highly functionalized cyclopentanes in which each and every carbon can be substituted as needed as exemplified by the synthesis of mannostatin A (18) (Scheme 2) (ref 13,17). The regioselective opening of the epoxide proved to be one of the most difficult aspects of this synthesis. We resorted to the acetonide 19 to control the conformation and thereby the regioselectivity of the epoxide ring opening. Indeed, the Fürst-Plattner effect in a bicyclo[3.3.0]octyl system favors the desired ring opening - a prediction that is experimentally verified. Desulfonylation then completes a simple practical synthesis of mannostatin A.

\section{ATOM ECONOMY}

Synthetic efficiency requires solving selectivity problems but should do so with efficient use of reactants. Thus, the evolution of reactions that are simple additions of two reactants such that their sum equals the product becomes the ultimate goal. Such reactions do exist and are among the most powerful in our encyclopedia of synthetic methods the Diels-Alder and aldol reactions being the most famous.

Transition metal complexes provide a simple selective way to activate $\mathrm{C}-\mathrm{H}$ bonds. Further, the high reactivity of acetylenes towards such complexes make them attractive substrates to search for such metal catalyzed addition reactions.

While acetylenes equilibrate with allenes under basic conditions, this equilibrium is much more selective in the presence of a transition metal. Interestingly, subjecting the propargyl acetate 20 to a Pd catalyst effects an unusual addition not at the triple bond but at the propargylic site, presumably through the intermediacy of an acetoxyallene (eq 17) (ref 18). Applying this new reaction to an intramolecular case effects a cycloisomerization for production of macrolactones.

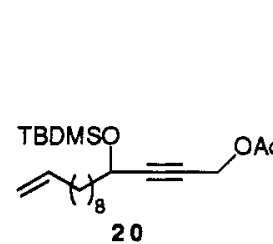

20<smiles>COc1ccccc1PC1CCCCC1</smiles>

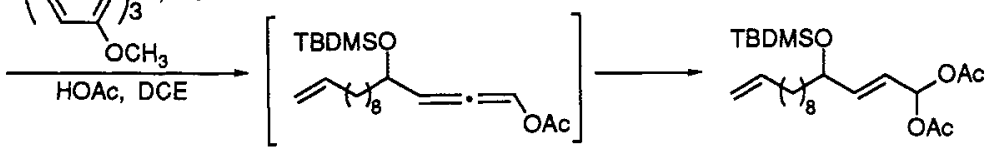


Transition metal complexes effectively insert into acetylenic hydrogen to generate a C-metal bond available for $\mathrm{C}-\mathrm{C}$ bond formation (eq 19). Eq 20 exemplifies the chemoselectivity of this new cross-condensation (ref 19). The intramolecular version, exemplified by a novel bis-cyclization in eq 21 (ref 20 ) proves to be particularly intriguing in

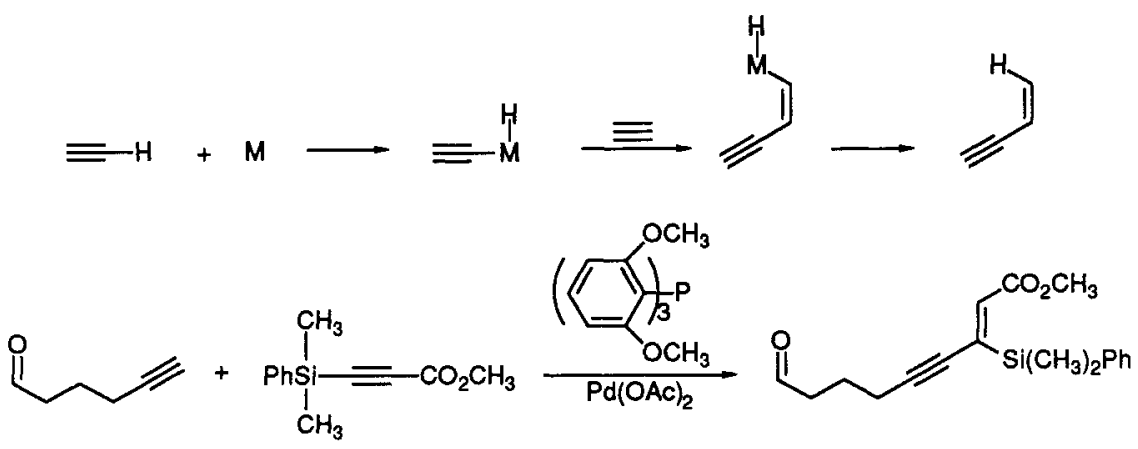

terms of chemoselectivity. In principle, either terminal acetylene of diyne $\mathbf{2 1}$ can serve as acceptor and/or donor;

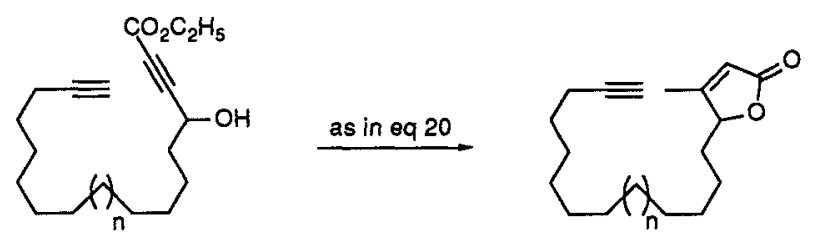

thus, both possible enynes 22 and 23 should be the expected products. A most remarkable selectivity is observed

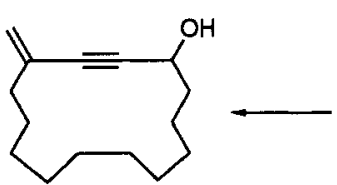

22<smiles>C#CCCCCCCCCCCC(O)C#C</smiles>

21

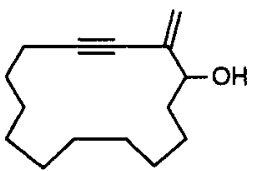

23

in that only $\mathbf{2 3}$ (eq 22) is produced. A free hydroxyl group is not required as exemplified by the chemoselectivity of
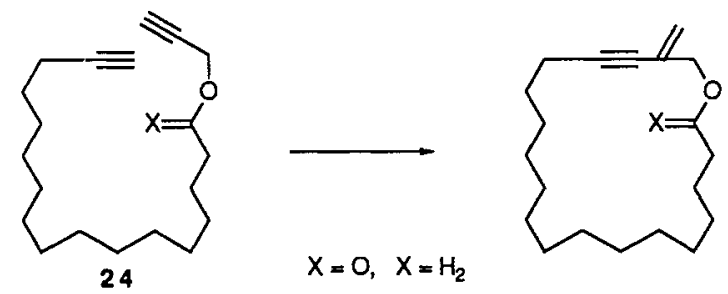

cycloisomerization of an acceptor acetylene by the presence of a nearby electron withdrawing group. Even a simple ether as in $\mathbf{2 4}\left(X=\mathrm{H}_{2}\right)$ suffices. Such subtle effects of abiological catalysis vividly demonstrates the delicate selectivities possible without the molecular complexity of biological catalysts.

Invoking the intermediacy of acetylide metal hydrides raises the question of the possible intervention of a

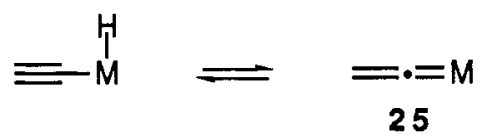

tautomer, the vinylidene complex 25 in catalytic cycles. Scheme 3 illustrates one such catalytic cyclic in which a

\section{Scheme 3}

\section{A Reconstitutive Condensation}

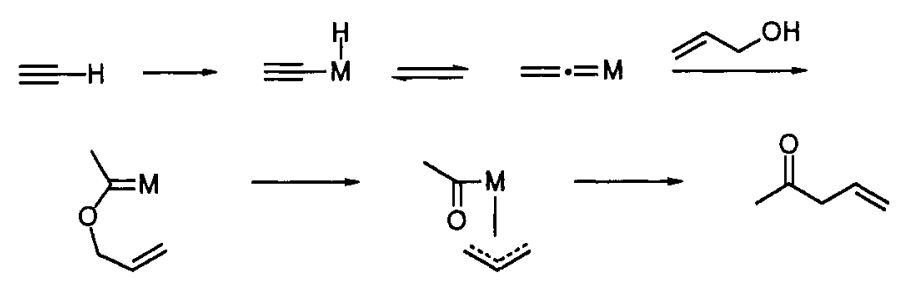


simple addition of allyl alcohol and a terminal acetylene occurs with reorganization of the oxidation pattern. Just such a reaction occurs with a simple nuthenium catalyst (eq 24) with high chemoselectivity (ref 22). Even non-allylic alcohols can be tolerated. On the other hand, propargylic alcohols are activated as leaving groups - a feature that permits

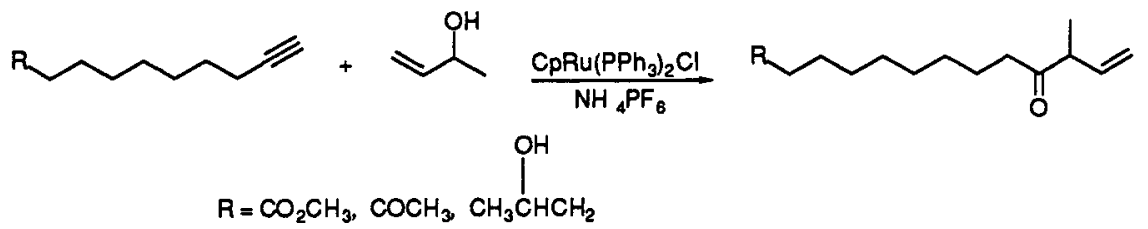

cyclization to tetrahydropyrans (eq 25) and tetrahydrofurans (eq 26) to accompany the addition (ref 23). More detailed mechanistic studies strongly support the initial concept of the reaction design of Scheme 3 (ref 24).<smiles>C#CC(O)C1CCCCC1CO</smiles>

\section{CONCLUSIONS}

Opportunitities abound to tremendously enhance our capability of synthesizing ever more complicated molecular targets by the evolution of increasingly selective methods. In doing so, we must be more cognizant of making such methods more economical in terms of atom count. Catalysis clearly will piay an ever increasing role in achieving these goals. The nature of the problems assures that both biological and abiological catalysis will be important.

\section{Acknowledgement}

My greatest thanks go to the outstanding group of graduate and postdoctoral students who have realized this chemistry. They are individually identified in the references. Financial support derives from the National Science Foundation and the National Institutes of Health, Institute of General Medical Sciences.

\section{REFERENCES}

1. B.M. Trost, Angew. Chem. Int. Ed. Engle. 28, 1173 (1989).

2. A. Della Cort, unpublished observations in these laboratories.

3. L.T. Phan, unpublished observations in these laboratories.

4. C. Brzezowski, unpublished observations in these laboratories.

5. B. Vos, unpublished observations in these laboratories.

6. N. Greeves, unpublished observations in these laboratories.

7. B.M. Trost, J.K. Lynch, S.R. Angle Tetrahedron Lett. 28, 375 (1987).

8. B.M. Trost, A.R. Sudhakar J. Am. Chem. Soc. 109, 3792 (1987).

9. B.M. Trost, A.R. Sudhakar J. Am. Chem. Soc. 110, 7933 (1988).

10. B.M. Trost, P.H. Lee J. Am. Chem. Soc. 113, 0000 (1991).

11. B.M. Trost, D.J. Murphy Organometallics 4, 1143 (1985).

12. B.M. Trost, D.L. Van Vranken J. Am. Chem. Soc. 112, 1261 (1990).

13. B.M. Trost, D.L. Van Vranken, unpublished observations in these laboratories.

$14 \mathrm{~L}$. Li, unpublished observations in these laboratories.

15. S. Sakuda, A. Isogai, S. Matsumoto, A. Suzuki J. Antibiot. 40, 296 (1987); S. Sakuda; A. Isogai; S. Matsumoto; K. Koseki; H. Kodama; Y. Yamada Agric. Biol. Chem. 1988, 52, 1615.

16. J. Maloisel, A. Vasella, B.M. Trost, D.L. Van Vranken, submitted for publication.

17. H. Morishima; K. Kojiri; T. Yamamoto; T. Aoyagi; H. Nakamura; Y. litaka J. Antibiot. 42, 1008 (1989).

18. W. Brieden; K. Baringhaus, unpublished observatons in these laboratories.

19. B.M. Trost; C. Chan; G. Rühter J. Am. Chem. Soc. 109, 3486 (1987).

20. B.M. Trost; S. Matsubara; J. Caringi J. Am. Chem. Soc. 111, 8745 (1989).

21. J.A. Tucker, unpublished observations in these laboratories.

22. B.M. Trost; G. Dyker; R.J. Kulawiec J. Am. Chem. Soc. 112, 7809 (1990).

23. J.A. Flygare, unpublished observations in these laboratories.

24. R.J. Kulawiec, unpublished observations in these laboratories. 